Article

\title{
Assessing Upper Tropospheric Jet Streak Proximity Using the Rossby Radius of Deformation
}

\author{
Joshua S. Kastman ${ }^{1}$, Patrick S. Market ${ }^{1}$, Scott M. Rochette ${ }^{2}$ and Anthony R. Lupo ${ }^{1, *}$ \\ 1 Department of Atmospheric Science, University of Missouri, Columbia, MO 65211, USA; \\ jskmd3@missouri.edu (J.S.K.); marketp@missouri.edu (P.S.M.) \\ 2 Department of the Earth Sciences, The College at Brockport, State University of New York, \\ Brockport, NY 14420, USA; rochette@esc.brockport.edu \\ * Correspondence: lupoa@missouri.edu; Tel.: +1-573-489-8457
}

Academic Editor: Robert W. Talbot

Received: 26 September 2016; Accepted: 20 December 2016; Published: 29 December 2016

\begin{abstract}
The Rossby radius of deformation is a parameter that describes the relative role of buoyant and inertial forces for atmospheric phenomena in a flow regime. It will be demonstrated that it can also be used to determine whether or not forcing for vertical motions in the region between upper level tropospheric jet streaks overlaps or interacts. Using predefined points in the entrance and exit regions of neighboring upper level jet streaks, the distance between them is calculated for each event. If they are closer than twice the Rossby radius of deformation, the resulting region affected by both streaks is termed the Rossby Radius of Deformation Overlap Zone (RRDOZ). Plan-view and cross-sectional analysis shows that ageostrophic transverse circulations within the RRDOZ led to enhanced upward vertical velocities as predicted in prior research. Lastly, a short-term climatology for overlap events in North America is derived, and these are classified according to three proposed archetypes.
\end{abstract}

Keywords: jet streaks; climatology; interaction; Rossby radius of deformation

\section{Introduction}

A recurring question when operationally or observationally diagnosing the upper tropospheric flow is: how close is close enough for two jet maxima to be considered coupled? The term 'coupled jet streaks' here refers to two individual local jet maxima whose influence may be overlapping and/or are synergistically impacting each other, and thus the resultant weather. Jet streaks are isotach maxima that occur within a jet stream as defined by [1]. Figure 1, which was inspired by [2], shows a three-dimensional schematic of two jet maxima aligned in such a manner that interaction is occurring. The work of [2] used eight cases studies to subjectively demonstrate this concept, but did not quantify a critical distance between the two jet maxima for synergistic interaction to be taking place. This question beseeches an answer since these overlapping jet streaks often lead to significant precipitation events and powerful mid-latitude cyclones. Several studies [2-6] provide substantial evidence suggesting the region in-between jet streaks is of major concern for enhanced precipitation and cyclogenesis, and occurs frequently over the Continental United States [7].

Jet streaks are often, but not always, associated with cyclogenesis. Cyclogenesis has been studied analytically as a baroclinic instability problem, as well established in seminal works [8,9]. Then, subsequent studies considered baroclinic instability as represented by cyclogenesis resulting from the interaction between an upper tropospheric disturbance and a surface disturbance, and among these are [10-12]. Often, this interaction is thought of as the upper level disturbance interacting with the lower one, a situation referred to as top-down development, or so-called Petterson "type B" cyclone behavior [13]. These quasigeostrophic primitive equation models commonly solved elliptical wave-equations (e.g., quasigeostrophic, barotropic vorticity or potential vorticity equations) using 
normal modes, as was done in [12], or the continuous spectrum following [10]. In either case, disturbances can interact if they are deep enough into the troposphere (e.g., the parameter Rossby height or depth), and these disturbances subsequently grow, decay, or simply propagate depending on the complex value (imaginary part) of the wave phase speed, as demonstrated by [14]. Similar behavior can be represented in the horizontal plane for the barotropic instability problem, as shown in $[15,16]$.

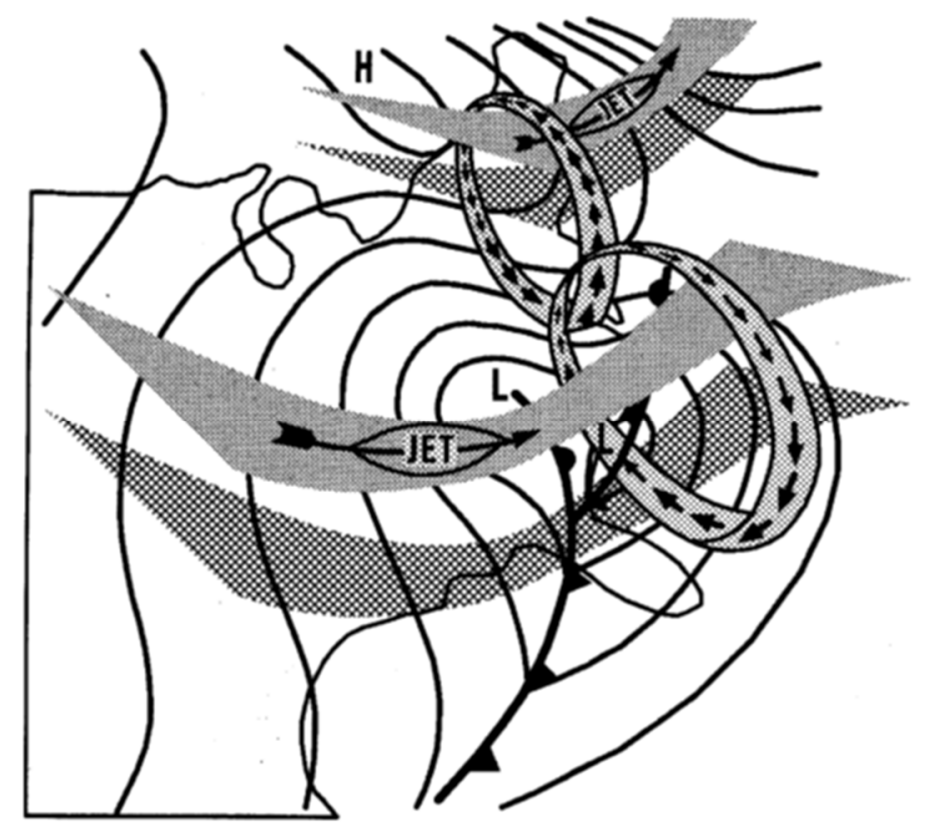

Figure 1. Three-dimensional schematic of jet-related circulation patterns during East Coast snowstorms. The transverse circulations are associated with diffluent exit and entrance regions of jet streaks embedded, respectively, at the bases of troughs moving across the Ohio and Tennessee valleys and across southeastern Canada. Surface low and high pressure systems, isobars, and frontal positions are also included (reproduced from [2]).

Other studies demonstrate interaction between phenomena of differing spatial or temporal scales by partitioning the observed atmospheric flow into two separate scales in time, space, or both, in the horizontal plane. Thus, an interaction term will arise from all product terms (the advection terms as part of a total derivative, for example, in a vorticity equation). This technique has already been used to study the relative contributions by synoptic and planetary-scale waves in block formation or maintenance and their interactions [17], speculating that Northern Hemisphere blocking events represent the mutually synergistic action between synoptic-scale cyclones and large-scale ridging based on the strength of the interaction term. They also postulated that Southern Hemisphere events are the result of constructive interference between each scale.

The purpose of this contribution is to answer the question, how close do overlapping jet streaks have to be in order to consider the transverse circulation coupled in an observational environment? These authors are not aware of any studies that use the methodologies employed here. This will be accomplished by examining the separation between the jet maxima compared to the Rossby radius of deformation. The Rossby radius of deformation is the length scale at which buoyant forces and rotational effects (Coriolis Effect) are equally influential in a flow about an embedded disturbance [14]. The Rossby radius of deformation could also be considered the spatial domain over which an atmospheric disturbance may impact the flow in which it is embedded. Therefore, when multiple disturbances are present, the possibility exists for an area to be impacted by multiple disturbances (as is the case with upper-level jet streak coupling). When this happens, a Rossby radius 
of deformation overlap zone (RRDOZ) may exist. If a RRDOZ exists, jet streaks have the potential to synergistically work together to generate impactful weather.

This study will test to see if the presence of a RRDOZ indicates that jet streaks are coupled. This will be determined by following methods similar to those in a previous work [2] in order to analyze the ageostrophic transverse circulation patterns and column-maximum upward vertical motion values within the RRDOZ for several cases. The end goal is to determine the necessary minimum distance between proximal jet streaks for a RRDOZ to exist, and if the RRDOZ indicates upper-level jet streak coupling. In order to achieve this goal, the following objectives will be accomplished; (1) determine if a RRDOZ exists for the cases examined; (2) test to see if ageostrophic transverse circulations are working together to create a region of enhanced vertical motions; and (3) characterize three archetypes for jet streak coupling over North America.

\section{Data and Methods}

The years 2002 through 2012 were examined for case selection. Daily $250 \mathrm{hPa}$ and $300 \mathrm{hPa}$ isotach analyses were inspected at the standard synoptic times, 0000 UTC and 1200 UTC. Cases were selected if there were two independent jet streaks present and they were aligned in a manner in which;

(1) the jet streaks had minimal curvature along their longer, along-stream horizontal axes;

(2) they were separated by at least one quarter wavelength of a trough or ridge;

(3) The potential coupled region (not necessarily the entire jet streaks) occurred over the Continental United States.

Some cases initially selected were dismissed because of an additional jet streak(s) in the vicinity, or because one of the jet streaks had exhibited more curvature than initially thought. In cases where there was an additional jet streak(s), it was eliminated because this case could influence the circulation pattern and the ageostrophic response to the jet streak. Cases that exhibited excessive curvature were removed because the typical divergence patterns that are associated with curved jet streaks are shown to be more erratic by some studies [18-20], and they could be vastly different from straight line jet streaks, thus making the testing for a RRDOZ difficult. Therefore, those cases were eliminated subjectively. Cases were also not examined if any part of the event occurred substantially outside the domain described below. The total number of cases that met the criteria and had adequate data availability for analysis was 59. The number of cases rejected for excessive curvature or the presence of multiple jet streaks was 45 , and most of these were due to curvature $(74 \%, 33 / 45)$ or the presence of more than two jet streaks $(20 \%, 9 / 45)$. Only three cases (of the 45$)$ were too far outside the domain. Thus, only $56 \%$ of all cases met the criteria defined here for the study of interaction.

The National Centers for Environmental Prediction (NCEP) North American Regional Reanalysis (NARR) was the data set employed as the gridded data source [21]. The NARR represented a single, unified reanalysis for the Continental United States. Moreover, the NARR grid spacing of $32.5 \mathrm{~km}$ is sufficient for this study because we are concerned with features that are on the meso- $\alpha$ to meso- $\beta$ scale.

The main quantity used here is the Rossby radius of deformation discussed in the introduction, and an in-depth discourse on this quantity is discussed in [14]. The Rossby radius of deformation as used here is a scaling parameter used to analyze the internal dynamics of fluids (see the Glossary of Meteorology [22]). This is the second definition in [22] which states in part; "An internal Rossby radius of deformation can be defined for fluids..." Alternative formulations do exist for other applications [22]. The Rossby radius of deformation can be used for forecasting or operational applications, such as for diagnosing tropical cyclogenesis [23].

Then, Bluestein [24] discusses the Rossby radius of deformation by exploring the effects of geostrophic disturbances in terms of $\mathbf{Q}$ vectors. Bluestein [24] also states that such disturbances force the atmosphere out of thermal wind equilibrium as $Q$ vectors deform the thickness field. Bluestein further notes that without ageostrophic and/or vertical motions, geostrophic thermal and vorticity advections destroy thermal wind balance. The destruction of balance gives rise to ageostrophic motions 
and divergence and convergence patterns. Note that the ageostrophic adjustment process actually can act to restore a geostrophic (or some other balanced) state over time as stated by [25]. Additionally, Bluestein [24] demonstrated that the Rossby radius of deformation is the length-scale out to which the impact of a disturbance becomes relatively small. The Rossby radius of deformation $\left(L_{R}\right)$ is expressed here as in [14]:

$$
L_{R}=\frac{N H}{f_{0}}
$$

where $N$ is the Brunt-Väisälä frequency, $H$ is the scale height, and $f_{0}$ is the Coriolis parameter.

Thus $L_{R}$ is a function of stability, temperature, and latitude. This work makes use of a single $L_{R}$ for all of these cases assuming that jet streaks are embedded within a typical mid-latitude synoptic-scale flow regime. The value used for $L_{R}$ is guided, in part, by the analysis of the general character of these mid-latitude flow regimes. These cases were generally located within five degrees of $42.5^{\circ} \mathrm{N}$ and the typical mean tropospheric (US standard) lapse rate was $6.5 \mathrm{~K} \cdot \mathrm{km}^{-1}$. Using these characteristic values for the mid-latitude atmosphere background flow (see [26,27]), a $L_{R}$ of $1136 \mathrm{~km}$ was computed. Each case of potential jet coupling was then evaluated to determine if the jet streak's divergent regions were within $2272 \mathrm{~km}$ of each other. Examining the potential for error in making these assumptions in estimating $L_{R}$ revealed that the quantity is most sensitive to the choice of latitude. Thus, the value of $L_{R}$ across the meridional direction of the domain varies by about $20 \%$. However, the choice of a middle latitude does not result in the inclusion or exclusion of additional cases examined here.

The points used to assess the Rossby radius of deformation will be referred to as the upstream jet streak point, and the downstream jet streak point. The upstream jet streak point refers to the jet streak contributing the indirect thermal circulation to the potentially coupled jet pair. The downstream jet streak point refers to the jet streak contributing the direct thermal circulation to the potentially coupled jet pair. For the Northern Hemisphere, the downstream jet streak was typically eastward and poleward of the upstream jet streak. Isotachs contoured every $5 \mathrm{~ms}^{-1}$ (10 knots) were used to assess the jet streaks. The downstream jet streak point was placed on the furthest position west on the first closed isotach of the poleward jet streak. The upstream jet streak point was established at the furthest position east on the first closed contour of the equatorward jet streak. The locations of these points were selected because they represent the beginning of the entrance (for a downstream jet streak) and end of the exit (for an upstream jet streak) regions for the given jet streaks.

A buffer was then created around each point with a radius equal to the $L_{R}$ value used for this study $(1136 \mathrm{~km})$ using the Aeronautical Reconnaissance Coverage Geographical Information System (ArcGIS) software package (Version 10.1) licensed to the University of Missouri. In particular, the data were plotted using ArcMAP which can be used to determine distance between two data points. The placement of these entrance (exit) regions is where the transverse circulations can be found according to [28]. The jet streak had to have at least one closed isotach greater than $30 \mathrm{~m} \cdot \mathrm{s}^{-1}(60 \mathrm{knots})$ and at least $5 \mathrm{~m} \cdot \mathrm{s}^{-1}$ in excess of the jet stream it was within (represented by least one closed contour). Case to case, the minimum closed isotach could vary, but each jet streak always has at least $5 \mathrm{~m} \cdot \mathrm{s}^{-1}$ in excess of the jet stream. For example, Figure 2 depicts a case that occurred on 27 January 2009. In this case, the closed isotachs around the jet streak were $35 \mathrm{~m} \cdot \mathrm{s}^{-1}$ (70 knots). This occurred within a jet stream flow of $30 \mathrm{~m} \cdot \mathrm{s}^{-1}$ (the $25 \mathrm{~m} \cdot \mathrm{s}^{-1}$ (50 knot) isotach is also shown), thus satisfying the condition of the jet streak being $5 \mathrm{~m} \cdot \mathrm{s}^{-1}$ in excess of the jet stream.

Figure 2 shows an example of the resulting RRDOZ by way of intersecting $L_{R}$ buffers. The image shows how the $L_{R}$ buffers are centered at the entrance (downstream jet streak) and exit (upstream jet streak) regions of the jet streaks. Once these points were established for each jet streak pair, a buffer was created around each point with a radius equal to the $L_{R}$ value $(1136 \mathrm{~km})$. If an overlap in these buffers existed, then a RRDOZ was present and the jet streaks were impacting one another. A vertical cross section was then taken through the RRDOZ to reveal if strong transverse ageostrophic circulations existed, overlapped, and created an enhanced region of upward vertical motion of $\left(\leq-5 \mu \mathrm{b} \cdot \mathrm{s}^{-1}\right)$ within the RRDOZ (Figure 2). An example of this can be seen in Figure 3, which depicts a cross section 
taken through the RRDOZ for the case of 9 December 2009. The cross section reveals a clear direct and indirect circulations in the ageostrophic circulation vectors.

This overlap could be constructive or synergistic in the same sense as [17] discussed in the introduction. It could be shown using the techniques in [17,25], or [29] that the overlapping divergence region or the forcing could be expressed as resulting from the sum of the contributions by each jet maximum and their interactions. This can be accomplished easily if the geopotential ( $\mathrm{gz}=\phi)$ in the overlap region is assumed to be partitioned among a contribution from each maximum $\left(\phi 1_{\max }, \phi 2_{\max }\right)$ as well as an interaction term $\left(\phi_{\text {int }}\right)$ as done by [27] or [30]. Thus, the divergent region in an overlap case is at least partially due to the contribution of each jet maximum and the divergence would be larger than if there were only one maximum present. Actual calculations are beyond the scope of this study, as the goal here is to simply identify overlap within the Rossby radius of deformation. Figure 3 also shows a region of upward vertical motion of $\leq-5 \mu \mathrm{b} \cdot \mathrm{s}^{-1}$ where the indirect and direct ageostrophic circulation vectors align to form a unified-branch of vectors pointing upward. This vertical motion threshold was chosen in accordance with the studies of [2,31].

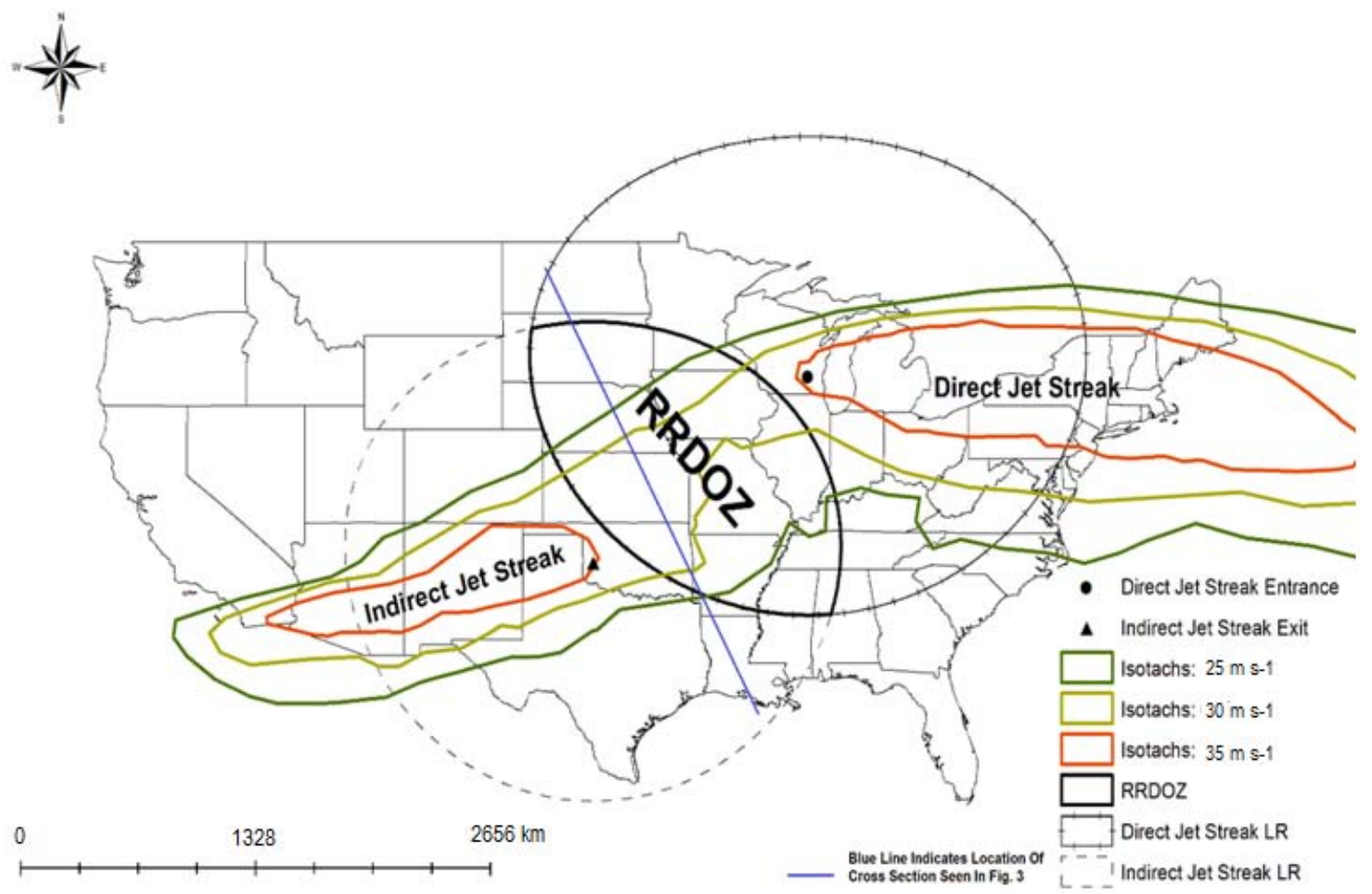

Figure 2. Example of Rossby Radius of Deformation Overlap Zone (RRDOZ) region as a result of intersecting $L_{R}$ buffers around the entrance (direct buffer black circle with vertical ticks) and exit (indirect buffer black dashed circle) regions of the potentially coupled jet streaks at $250 \mathrm{hPa}$. Green isotachs are $25 \mathrm{~m} \cdot \mathrm{s}^{-1}$ (50 knots), gold isotachs are $30 \mathrm{~m} \cdot \mathrm{s}^{-1}$ (60 knots), and red isotachs are $35 \mathrm{~m} \cdot \mathrm{s}^{-1}$ (70 knots). The solid circle represents the center of the direct jet streak Rossby radius of deformation buffer, while the black solid triangle represents the center of the indirect jet streak Rossby radius of deformation buffer. The solid blue line from North Dakota to the Gulf Coast of Louisiana is a cross section line. This case occurred on 27 January 2009 (Case 38 see Appendix A).

In order to assess the sensible weather impact, US Daily Weather Maps [32] are examined and a maximum precipitation amount associated with the RRDOZ region is determined and archived in Appendix A. Since these maps provide contoured precipitation amounts, the largest contour found within the RRDOZ region is used for the amount given here. The map corresponding to Figure 2 is shown in Figure 4. 


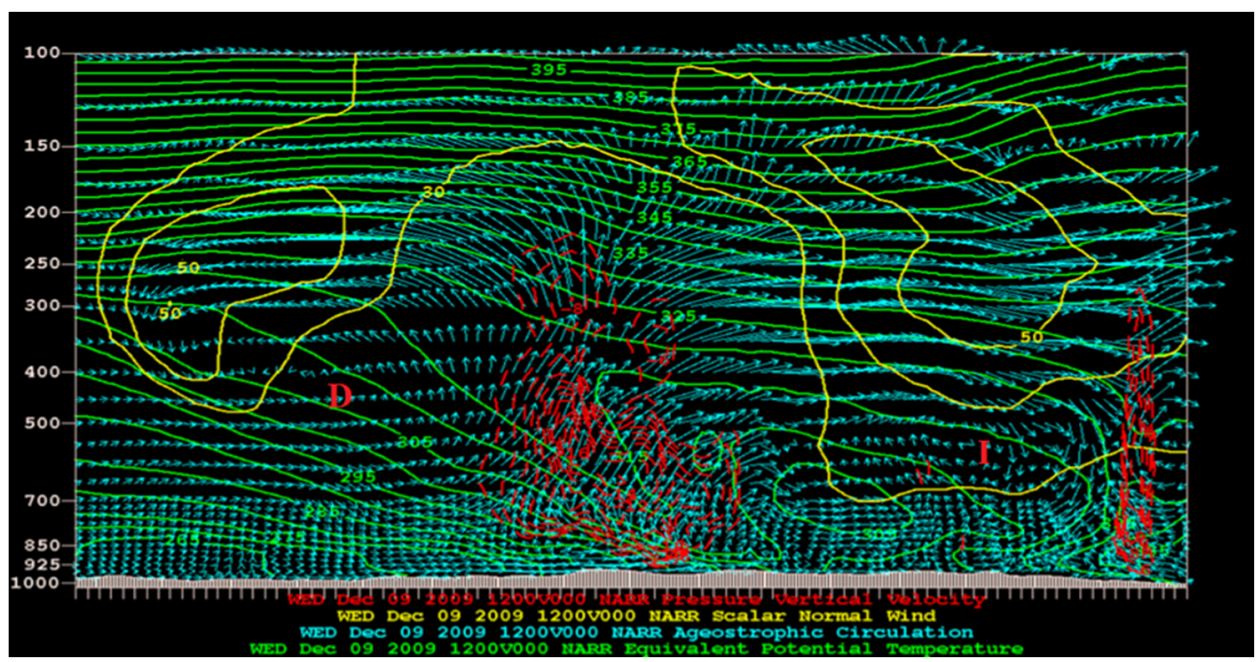

Figure 3. Cross section through a RDDOZ on 1200 UTC 9 December 2009. Dashed green lines are values of equivalent potential temperature $\left(\theta_{\mathrm{e}}\right)$ every $5 \mathrm{~K}$. Light blue arrows are ageostrophic circulation vectors. Solid yellow lines are isotachs normal to the cross section $10 \mathrm{~m} \cdot \mathrm{s}^{-1}$. D and I represent the thermally direct (downstream) and indirect (upstream) circulations, respectively. Red arrows represent vertical velocity vectors.

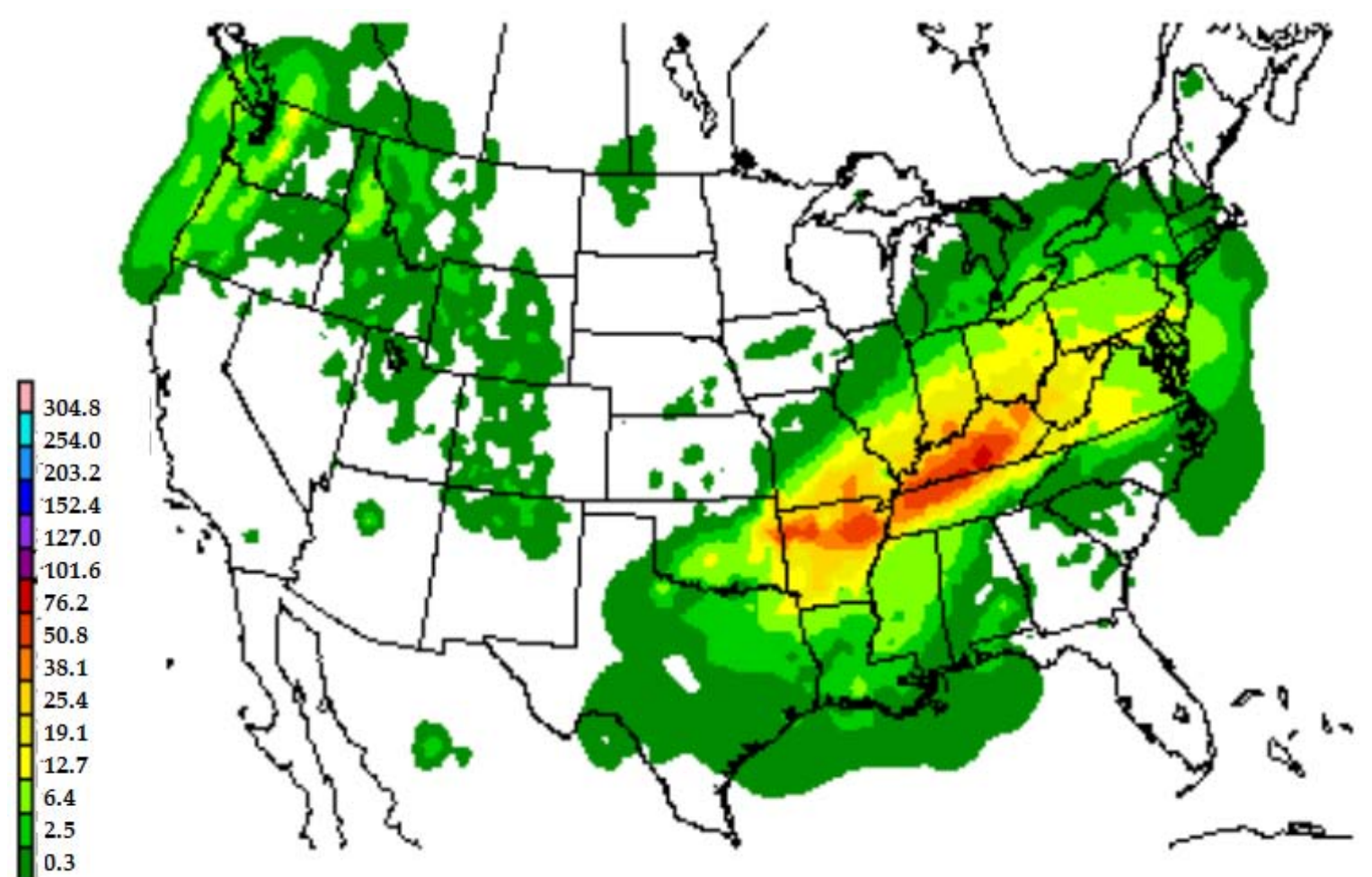

Figure 4. Contoured $24 \mathrm{~h}$ precipitation (mm) ending at 1200 UTC 28 January 2009 [32].

\section{Results and Analysis}

Analysis revealed that in all 59 cases there existed a Rossby radius of deformation overlap zone (RRDOZ) lasting at least six hours. The cases varied between $6 \mathrm{~h}$ to $36 \mathrm{~h}$ where the conditions for coupling were met. This result demonstrates that in all cases the investigated jet streaks were within the Rossby radius of deformation and therefore could influence one another. 
At first, this result may seem unlikely when one considers the typical Rossby radius of deformation for the Continental United States is $1136 \mathrm{~km}$. However, since there are two jet streaks involved, that number is doubled to $2272 \mathrm{~km}$, which is large enough to fully resolve a synoptic-scale wave. Jet streaks tend to form just upstream or downstream of the apex of ridge or base of a trough in meridional flow (when jet streaks form around the base of a trough or apex of a ridge, they generally exhibit strong curvature). This translates to jet streaks forming, in many cases, approximately $\frac{1}{2}$ wavelength (synoptic-scale wave $\sim 1000 \mathrm{~km}$ ) apart. This value is close to the value of the Rossby radius of deformation that was used $(1136 \mathrm{~km})$. In zonal flow the jet streaks tend to form near shortwaves within the flow. In these cases, the jet streaks are farther apart but still within $2000 \mathrm{~km}$ of one another.

Furthering this result, all cases contained periods of at least $3 \mathrm{~h}$ in which column maximum upward vertical motion- $\omega \leq-5 \mu \mathrm{b} \cdot \mathrm{s}^{-1}$ exist within the RRDOZ. This shows that there is ascending air occurring within the region between the jet streaks, strongly indicating that the coupled jet streaks are forcing enhanced rising motion via ageostrophic transverse circulations. Figure 3 reveals that the ageostrophic transverse circulation is indeed between the two jet streaks, resulting in an enhanced region of upward vertical velocity (labeled $\omega$ in Figure 3). It appears that when straight jet streaks are present and are aligned approximately $\frac{1}{2}$ wavelength apart, rising motion results in response to the collocation of the ageostrophic transverse circulations. In all of these cases the jet streaks could both influence the resultant forcing. Therefore, one may proceed with the assumption that if two straight jet streaks in the same wave are present that the jet streaks are close enough to be coupled.

This work also revealed three patterns of jet streak overlap formations. Figure 5 shows the three archetypes of jet streak coupling that were apparent in this study. The three typical formations of coupled jet streaks were called; (1) parallel stacked; (2) $135^{\circ}$ type; and (3) $90^{\circ}$ type. Appendix A contains a list of all events examined here and characteristics such as the archetype and location. The parallel stacked formation was the most common alignment at $58 \%(34 / 59)$. The $135^{\circ}$ type was the second most common at $31 \%(18 / 59)$. The $90^{\circ}$ type was less common with only $8 \%(5 / 59)$. Finally, two cases transitioned between types during their lifespan and accounted for only $3 \%$ of all cases $(2 / 59)$.

Not surprisingly, jet streak coupling occurred most during meteorological winter months (December through February) at 37\% (22/59), followed by spring (March through May) at 28\% (16/59), fall (September through November) at 20\% (12/59), and lastly the summer (June through August) at $15 \%(9 / 59)$. The majority of winter (15/22) and spring (10/16) were parallel stacked, while for summer and fall events parallel stacked and $135^{\circ}$ events occurred equally as often.

In order to examine where these cases were most often located, the Continental United States was broken down into three sub-regions: the West Pacific Coast and Rocky Mountain States (Montana, Wyoming, Colorado, and New Mexico), the East (Appalachian States and Atlantic Coast), and the Central region. The majority of cases at $69 \%(41 / 59)$ occurred over the Central region. Only $20 \%(12 / 59)$ and $11 \%(6 / 59)$ of cases occurred over the East and West sub-regions, respectively. This may at least partly be a function of the choice of the larger study region and/or the availability of data. Examining the distribution of types in each region showed it was similar to the overall distribution within the larger domain.

It was also noted that the majority of cases occurred within a meridional $500 \mathrm{hPa}$ height pattern $(64 \%, 38 / 59)$, with the remaining cases associated with zonal flow. Furthermore, it was found that the majority of coupling events were of relatively short duration: $61 \%$ of the events lasted between three and $12 \mathrm{~h}$, with the remaining cases having lifetimes up to $36 \mathrm{~h}$. Lastly, there was no correlation between the maximum wind speeds in the jet streaks and the RRDOZ.

Assuming that jet streaks are interacting based on their proximity is a powerful assumption, and all of these cases exhibited column maximum vertical motions $\left(\omega \leq-5 \mu \mathrm{b} \cdot \mathrm{s}^{-1}\right)$ during every single time step. This shows that there is an influence on upward vertical motion by these jet streaks when they are within RRDOZ. Additionally, cross-sections confirm the presence of interacting transverse ageostrophic circulations within the RRDOZ during every case. Not every time step within a case 
showed interacting transverse ageostrophic circulations, but every case had at least one time-step where there existed such interacting circulations.

Thus, all 59 of these cases are reasonably assumed to be coupled. As long as jet streaks are aligned, as in Figure 5, they could yield a region of enhanced upward motions greatly increasing the risk of significant sensible weather here defined as a region of measurable precipitation within the RRDOZ region similar to a previous study [28]. Appendix A shows that all but one case was associated with at least $12.7 \mathrm{~mm}$ of precipitation, and $29 \%$ of these $(17 / 59)$ were associated with at least $50 \mathrm{~mm}$ of precipitation. Of these higher precipitation cases, 15 of them were Central region cases, and two were Eastern region. Nine were parallel stacked, six were of $135^{\circ}$, and one each of the $90^{\circ}$ and transitional case.
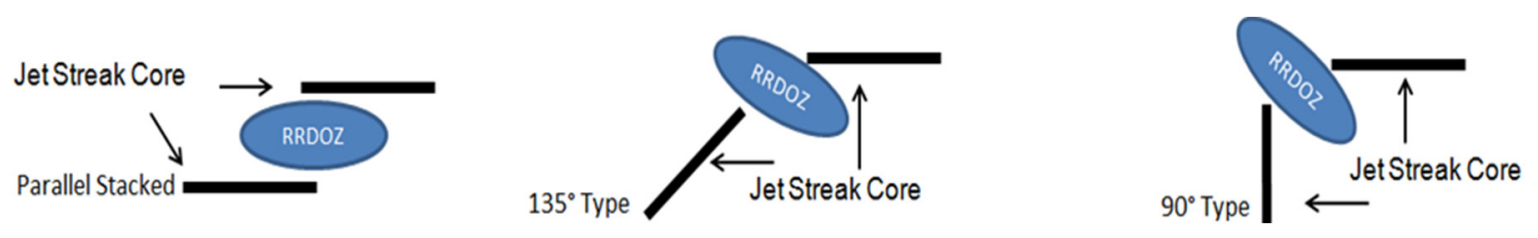

Figure 5. The three archetypes of jet streaks observed in the study.

\section{Conclusions}

The results of this study indicate that the Rossby radius of deformation is an effective way to test if jet streaks are jointly impacting the forcing field. Not only did each of the cases examined here exhibit a RRDOZ, but they also exhibited collocation of ageostrophic transverse circulations that resulted in enhanced areas of column-maximum vertical motions $\left(\omega \leq-5 \mu \mathrm{b} \cdot \mathrm{s}^{-1}\right)$. Thus, one may assume that when straight-line jet streaks are present in the upper troposphere in the same manner as in Figure 5, they are coupled and the region in question could expect a broad region of measurable precipitation as well as other sensible weather phenomena.

This study and its results are only valid for straight or quasi-straight jet streaks. Curved jet streaks were not tested and the results may differ for such cases. Indeed, it has been established by some studies [18-20] that curvature greatly affects the distribution of the upper-level divergence patterns and ageostrophic circulations. Future work on this subject needs to include curved jet streaks as they also occur frequently.

The three archetypes of upper-level straight-line overlapping jet streaks found in this study hold potential for further work to be done, especially regarding strength/severity of events and accompanying sensible weather. A study by [33] shows that the divergence equation for a baroclinic wave dictates that the divergence will be enhanced for a wave with a short wave-length and high amplification. Therefore, one expects the $90^{\circ}$ type and $135^{\circ}$ type formations to exhibit stronger divergence and perhaps upward vertical velocities than the parallel stacked cases. This has yet to be tested, but is an area that should be investigated in order to aid forecasters in becoming more aware of the potential for a broad region of impactful or dangerous weather.

Acknowledgments: The authors would like to thank the anonymous reviewers for their comments which helped to make this contribution stronger.

Author Contributions: Patrick S. Market and Scott M. Rochette conceived and designed the experiments along with Joshua S. Kastman; Joshua S. Kastman performed the experiments; all four authors analyzed the data and wrote the paper.

Conflicts of Interest: The authors declare no conflict of interest. 


\section{Appendix A.}

Table A1. List of cases included in the analysis. Included is the case number, date of occurrence, season, location, and archetype. Cases that were parallel stacked are Type 1 , the $135^{\circ}$ case is Type 2 , and the $90^{\circ}$ case is Type 3 . The last column is the maximum precipitation $(\mathrm{mm})$ contour found in the RRDOZ using the US Daily Weather Map series [32].

\begin{tabular}{|c|c|c|c|c|c|}
\hline Case Number & Date(s) & Season & Location & Archetype & Max Precip \\
\hline 1 & 6 January 2002 & Winter & East & 1 & 25.4 \\
\hline 2 & 16-17 January 2002 & Winter & West & 1 & 6.4 \\
\hline 3 & 26 April 2002 & Spring & Central & 2 & 25.4 \\
\hline 4 & 1-2 May 2002 & Spring & Central & 1 & 12.7 \\
\hline 5 & 11 May 2002 & Spring & Central & 1 & 76.2 \\
\hline 6 & 1 October 2002 & Fall & West & 1 & 25.4 \\
\hline 7 & 23-24 December 2002 & Winter & Central & 1 & 76.2 \\
\hline 8 & 4-5 March 2003 & Spring & Central & 1 & 25.4 \\
\hline 9 & 14-16 April 2003 & Spring & Central & 1 & 50.8 \\
\hline 10 & 4 July 2003 & Summer & Central & 2 & 25.4 \\
\hline 11 & $8-9$ July 2003 & Summer & Central & 1 & 76.2 \\
\hline 12 & 5 October 2003 & Fall & Central & 2 & 50.8 \\
\hline 13 & 13 December 2003 & Winter & Central & 2 & 50.8 \\
\hline 14 & 4-5 February 2004 & Winter & Central & 3 & 76.2 \\
\hline 15 & 10-11 April 2004 & Spring & East & 1 & 38.1 \\
\hline 16 & 17 May 2004 & Spring & Central & 1 & 38.1 \\
\hline 17 & 7 June 2004 & Summer & Central & 2 & 50.8 \\
\hline 18 & 15 February 2005 & Winter & Central & 1 & 12.7 \\
\hline 19 & 25 April 2005 & Spring & Central & 2 & 38.1 \\
\hline 20 & 25 September 2005 & Fall & Central & 1 & 38.1 \\
\hline 21 & 20 January 2006 & Winter & Central & 1 & 19.1 \\
\hline 22 & 25 February 2006 & Winter & Central & 1 & 50.8 \\
\hline 23 & 15-16 April 2006 & Spring & Central & 3 & 38.1 \\
\hline 24 & 4 July 2006 & Summer & Central & 2 & 38.1 \\
\hline 25 & 25 August 2006 & Summer & Central & 1,3 & 38.1 \\
\hline 26 & 15-16 January 2007 & Winter & Central & 1 & 19.1 \\
\hline 27 & 19-21 January 2007 & Winter & Central & 2 & 38.1 \\
\hline 28 & 13-14 February 2007 & Winter & East & 1 & 38.1 \\
\hline 29 & 14-16 April 2007 & Spring & East & 2 & 101.6 \\
\hline 30 & 26-27 December 2007 & Winter & East & 1 & 25.4 \\
\hline 31 & 29 January 2008 & Winter & West & 2 & 19.1 \\
\hline 32 & 6-9 March 2008 & Spring & Central & 1 & 38.1 \\
\hline 33 & 31 March 2008 & Spring & Central & 1 & 50.8 \\
\hline 34 & 8-9 April 2008 & Spring & Central & 1 & 50.8 \\
\hline 35 & 24 April 2008 & Spring & West & 1 & 19.1 \\
\hline 36 & 10 October 2008 & Fall & Central & 2 & 19.1 \\
\hline 37 & 11-12 November 2008 & Fall & Central & 2 & 101.6 \\
\hline 38 & 27 January 2009 & Winter & Central & 1 & 38.1 \\
\hline 39 & 26-27 February 2009 & Winter & Central & 1 & 38.1 \\
\hline 40 & 28-29 March 2009 & Spring & Central & 3 & 38.1 \\
\hline 41 & 6 May 2009 & Spring & West & 3 & 25.4 \\
\hline 42 & 1 July 2009 & Summer & East & 2 & 38.1 \\
\hline 43 & 12 July 2009 & Summer & East & 1 & 38.1 \\
\hline 44 & 12 August 2009 & Summer & West & 1 & 12.7 \\
\hline 45 & 12 September 2009 & Fall & Central & 1,2 & 50.8 \\
\hline 46 & 25 September 2009 & Fall & East & 2 & 50.8 \\
\hline 47 & 2-4 October 2009 & Fall & East & 1 & 38.1 \\
\hline 48 & 4 October 2009 & Fall & Central & 1 & 50.8 \\
\hline 49 & 6-7 October 2009 & Fall & Central & 3 & 38.1 \\
\hline 50 & 15 October 2009 & Fall & East & 1 & 25.4 \\
\hline
\end{tabular}


Table A1. Cont.

\begin{tabular}{cccccc}
\hline Case Number & Date(s) & Season & Location & Archetype & Max Precip \\
\hline 51 & 21-22 October 2009 & Fall & Central & 2 & 76.2 \\
52 & 9 December 2009 & Winter & Central & 1 & 25.4 \\
53 & 2 February 2011 & Winter & East & 2 & 19.1 \\
54 & 16-17 February 2011 & Winter & Central & 2 & 12.7 \\
55 & 20-21 February 2011 & Winter & Central & 1 & 25.4 \\
56 & 11-12 December 2011 & Winter & Central & 1 & 12.7 \\
57 & 23 January 2012 & Winter & Central & 1 & 25.4 \\
58 & 2 July 2012 & Summer & East & 1 & 38.1 \\
59 & 14 December 2012 & Winter & Central & 2 & 12.7 \\
\hline
\end{tabular}

\section{References}

1. Reiter, E.R. Jet Stream Meteorology; University of Chicago Press: Chicago, IL, USA, 2008; p. 433.

2. Uccellini, L.W.; Kocin, P.J. The interaction of jet streak circulations during heavy snow events along the East Coast of the United States. Weather Forecast. 1987, 2, 289-308. [CrossRef]

3. Rogers, J.; Bosart, L.F. A diagnostic study of two intense oceanic cyclones. Mon. Weather Rev. 1991, 119, 1084-1099. [CrossRef]

4. Hakim, G.J.; Uccellini, L.W. Diagnosing coupled jet-streak circulations for a Northern Plains snow band from the operational Nested-Grid Model. Weather Forecast. 1992, 7, 26-48. [CrossRef]

5. Lupo, A.R.; Nocera, J.J.; Bosart, L.F.; Hoffman, E.G.; Knight, D.J. The occurrence of cyclonic and anticyclonic cold surges. Mon. Weather Rev. 2001, 129, 1021-1041. [CrossRef]

6. Market, P.S.; Cissell, D. Formation of a sharp snow gradient in a Midwestern heavy snow event. Weather Forecast. 2002, 17, 723-738. [CrossRef]

7. Rochette, S.M.; Gravelle, C.M.; Market, P.S. Decomposition of the ageostrophic wind in cold-season coupled upper-level jet streaks. In Proceedings of the 33rd Annual Meeting of the National Weather Association, Louisville, KY, USA, 11-16 October 2008; p. 2.4. Available online: http://www.nwas.org/meetings/ abstracts / display.php?id=412 (accessed on 12 February 2016).

8. Charney, J.G. The dynamics of long-waves in a baroclinic westerly current. J. Meteorol. 1947, 4, $135-162$. [CrossRef]

9. Eady, E.T. Long waves and cyclone waves. Tellus 1949, 1, 33-52. [CrossRef]

10. Farrell, B. Modal and non-modal baroclinic waves. J. Atmos. Sci. 1984, 41, 668-673. [CrossRef]

11. Thorncroft, C.D.; Hoskins, B.J. Frontal Cyclogenesis. J. Atmos. Sci. 1990, 47, 2317-2336. [CrossRef]

12. Rivest, C.; Davis, C.A.; Farrell, B.F. Upper tropospheric synoptic-scale waves. Part I: Maintenance as Eady normal modes. J. Atmos. Sci. 1992, 49, 2108-2119.

13. Petterssen, S.; Sembye, S.J. On the development of extratropical cyclones. Q. J. R. Meteorol. Soc. 1971, 97, 457-482. [CrossRef]

14. Gill, A.E. Atmosphere-Ocean Dynamics; International Geophysical Series; Academic Press: London, UK, 1982; Volume 30, p. 662.

15. Kuo, H.L. Dynamic instability of two-dimensional nondivergent flow in a barotrpoic atmosphere. J. Meteorol. Res. 1949, 6, 247-300.

16. Egger, J. Barotropic Instability at minimum resolution. Mon. Weather Rev. 2006, 34, 2943-2950. [CrossRef]

17. Burkhardt, J.P.; Lupo, A.R. The planetary and synoptic-scale interactions in a Southeast Pacific blocking episode using PV diagnostics. J. Atmos. Sci. 2005, 62, 1901-1916. [CrossRef]

18. Shapiro, M.A.; Mesoscale Weather Systems of the Central United States. The National STORM Program: Scientific and Technology Bases and Major Objectives; Anthes, R.A., Ed.; University Corporation for Atmospheric Research: Boulder, CO, USA, 1982.

19. Keyser, D.; Shapiro, M.A. A review of the structure and dynamics of upper-level frontal zones. Mon. Weather Rev. 1986, 114, 452-499. [CrossRef]

20. Moore, J.T.; Van Knowe, G.E. The effect of jet-streak curvature on kinematic fields. Mon. Weather Rev. 1992, 120, 2429-2441. [CrossRef]

21. Mesinger, F. North American regional reanalysis. Bull. Am. Meteorol. Soc. 2006, 87, 343-360. [CrossRef] 
22. Glickman, T.S. Glossary of Meteorology, 2nd ed.; American Meteorological Society: Boston, MA, USA, 2000; p. 855.

23. Papin, P. Using the rossby radius of deformation as a forecasting tool for tropical cyclogenesis. In Proceedings of the National Conference on Undergraduate Research (NCUR), Ithaca College, Ithaca, NY, USA, 31 March-2 April 2011; p. 9.

24. Bluestein, H.B. Synoptic-Dynamic Meteorology in Midlatitudes: Principles of Kinematics and Dynamics; Oxford University Press: Oxford, UK, 1992; Volume 1, p. 431.

25. Lupo, A.R. The Role of Ageostrophic Forcing in a Height Tendency Equation. Mon. Weather Rev. 2002, 130, 115-126. [CrossRef]

26. US Standard Atmosphere. Available online: https://www.gpo.gov/ (accessed on 28 December 2016).

27. Hakim, G.J.; Bosart, L.F.; Keyser, D. The Ohio Valley wave-merger cyclogenesis event of 25-26 January 1978. Part 1: Multi-scale case study. Mon. Weather Rev. 1995, 123, 2663-2692. [CrossRef]

28. Uccellini, L.W.; Johnson, D.R. The coupling of upper and lower tropospheric jet streaks and implications for the development of severe convective storms. Mon. Weather Rev. 1979, 107, 682-703. [CrossRef]

29. Lupo, A.R.; Smith, P.J. Planetary and synoptic-scale interactions during the life cycle of a mid-latitude blocking anticyclone over the North Atlantic. Tellus A 1995, 47, 575-596. [CrossRef]

30. Trenberth, K.E.; Chen, S.C. Rotational and divergent geopotential components. J. Atmos. Sci. 1988, 45, 2949-2960. [CrossRef]

31. Rochette, S.M.; Moore, J.T. Initiation of an elevated mesoscale convective system associated with heavy rainfall. Weather Forecast. 1996, 11, 443-457. [CrossRef]

32. The US Daily Weather Maps Archive. Available online: http://www.lib.noaa.gov/collections/imgdocmaps / daily_weather_maps.html (accessed on 13 December 2016).

33. Moore, J.T.; Abeling, W.A. A diagnosis of unbalanced flow in upper levels during the AVE-SESAME I period. Mon. Weather Rev. 1988, 116, 2425-2436. [CrossRef]

(C) 2016 by the authors; licensee MDPI, Basel, Switzerland. This article is an open access article distributed under the terms and conditions of the Creative Commons Attribution (CC-BY) license (http://creativecommons.org/licenses/by/4.0/). 